\title{
Experimental research of apparatuses for peanuts and cocoa beans roasting with rotating-pulsed fluidized bed
}

\author{
Georgi Djourkov ${ }^{1 *}$, and Dimitar Hadjikinov ${ }^{1}$ \\ ${ }^{1}$ Department of Tobacco, Sugar, Vegetable and Essential Oils, University of Food Technologies, Plovdiv, Bulgaria
}

\begin{abstract}
The physical parameters of two products widely used in the confectionery industry - peanuts and cocoa beans - have been studied. The hydrodynamic characteristics of these products, influencing the fluidized bed roasting regime, have been determined. The hydrodynamics of a rotating-pulsed fluidization of the cited materials has been examined. Dependences are derived for calculating the bed pressure drops and the initial fluidization velocity of the particles during rotating-pulsed creation of fluidization.
\end{abstract}

\section{Introduction}

Peanuts and cocoa beans are the main raw materials in the production of confectionery [1, 2]. A particularly important operation in the processing of these raw materials is roasting $[3,4]$. The latter largely determines the aromatic and flavor features of the final product, the duration of storage and the release of volatile components with an unpleasant taste and odor [5].

Numerous apparatuses for roasting nuts and cocoa beans are known, and in recent years the most widely used devices are convective heating of products and particularly those with a fluidized bed [6]. The technological advantages of fluidized bed roasters also determine their wide distribution worldwide [7, 8]. The rotating-pulse supply of the heated air in the working chamber [9] provides additional advantages of the roasting apparatuses working on this principle:

- The forced periodic supply of gas acts with its high flow rate on the particles of the bed, which prevents formation of dead zones even during processing of polydisperse materials.

- The concentrated introduction (in narrow zones) of the main part of the fluidizing agent, through which a high local number of fluidization is achieved, significantly improves the mixing of the particles.

- An additional macro-movement of the particles along the depth of the chamber in the forward and opposite direction to the direction of movement of the fluidizing gas is created.

- The energy required to create a fluidized bed is reduced, as due to the above advantages, the opened area cross-section of the gas distribution device can be increased well above the permissible values for the traditional fluidized bed.

The hydrodynamic environment in fluidized bed apparatus is determined mainly by the physical characteristics of the processed materials, which affects the operating parameters of the process [10].

The main physical parameters of the products required for hydrodynamic research are: density - particle and bulk; average equivalent particle diameter; average volume and surface of the particles; particle shape factor; dispersion and porosity of the bed.

The main operating parameters of the fluidization process, affecting the design of fluidized bed apparatus calculations are: minimum fluidization velocity and pressure drops of the bed and the grid.

The aims of this study were to experimentally determine the basic physical parameters of the selected products, as well as to derive dependences for calculating the minimum fluidization velocity and the pressure drop of the fluidized bed, which can be used to calculate devices operating on the principle of rotating-pulsed fluidized bed.

\section{Materials and methods}

The materials used in the study were purchased commercially. The individual grains are cleaned manually from light and heavy impurities such as dust, stones, packaging residues, etc. as well as from broken and damaged grains.

The moisture content of the tested materials was determined by the weight method using Adam PMB-53 moisture analyzer. The measurement of the physical parameters was performed at a moisture content suitable for long-term storage of raw materials, respectively: $6,5 \%$ for peanuts and $6.9 \%$ for cocoa beans.

The dimensions of the individual grains were measured with a digital caliper TESA with serial 6R 1596 01 with an accuracy $\pm 0.01 \mathrm{~mm}$. The measurement was performed with 100 grains from each product [11]. To simplify the determination of the average equivalent

\footnotetext{
* Corresponding author: george.djurkov@gmail.com
} 
particle diameter, a new method has been developed. The volume and surface were calculated for a stylized shape of every particle by drawing it in a three-dimensional modeling software (in this case SolidWorks ${ }^{\circledR}$ is used).

When making the stylized model, the particle shape is assumed to be symmetrical and is determined by two or three basic sizes - D and $\mathrm{H}$ for peanuts (Fig. 1) and B1, B2 and $\mathrm{H}$ (Fig. 2) for cocoa beans. After stylized model is built, a design table is made in which all measurements of the nuts required by the method are reflected - 100 pieces of each product. Subsequently, the capabilities of the software are used to calculate the volume and surface area of all particles simultaneously, and the results are averaged.

The method used is suitable for products with a similar shape of the individual particles but differ in the average linear dimensions. These are almonds, hazelnuts, soy, sesame, and others. For the tested products the method showed $99 \%$ accuracy compared to the classical methods.

The particle density was determined by the pycnometric method, and the bulk density was measured by determining the mass of a given volume of bulk particles [12].

The particle shape factor, the dispersion, and the initial porosity of the bed, as well as the Archimedes criterion are calculated according to the respective dependencies $[13,14]$.

The material bed pressure drop was measured by the direct method [15] using a micro-manometer MMN-250 with an accuracy of $\pm 5 \mathrm{~Pa}$.
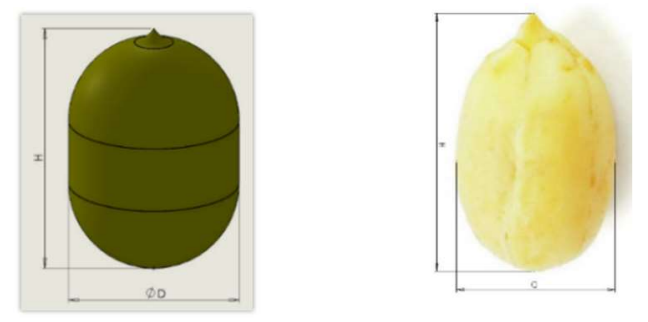

Fig. 1. Peanut.
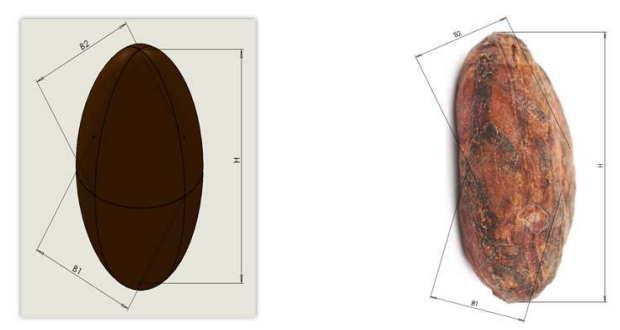

Fig. 2. Cocoa bean

\section{Results and discussions}

The results of the measurements of the physical parameters and the calculated values are presented in Table. 1. To study the hydrodynamics of the rotatingpulsed fluidized bed, a total of 54 experiments were conducted including 27 with each of the two types of materials - peanuts and cocoa beans. For each of the materials it is varied with the following parameters of the granular bed and the structural dimensions of the elements creating the rotating-pulsed fluidization:

- The load of the bed on the supporting grid $(m / F)$. Three batches of 2, 3 and $5 \mathrm{~kg}$ were selected then the loads of the supporting grid sere calculated respectively - 64, 96 and $159 \mathrm{~kg} / \mathrm{m}^{2}$;

- The speed of rotation of the gas distribution disk. Three values were used: 23, 55 and $110 \mathrm{rpm}$.

- The opened area cross-section of the gas distribution disk. Two disks with an opened area cross-section of 12.6 (two openings) and 7.2\% (one opening) were made.

- the opened area cross-section of the supporting grid. Two types of supporting grids are used - braided wire mesh with an opened area cross-section of $67 \%$ and perforated sheet metal with an open area cross section of $30 \%$.

The increase in the bed pressure drops with increasing velocity of the fluidizing agent relative to the entire cross section of the working chamber is represented graphically by the fluidization curve. This curve is an important characteristic of fluidized systems.

The Fig. 3 and the Fig. 4 show the fluidization curves of peanuts and cocoa beans, respectively.

These figures show that the nature of the change in the pressure drop of the bed with increasing air velocity is similar to that of the fluidization curves for the traditional fluidized bed. At high beds $\left(m / F=96\right.$ and $\left.159 \mathrm{~kg} / \mathrm{m}^{2}\right)$ the characteristic peak of pressure drops during transition from static to fluidized state is observed, but this peak is smaller than the same at the traditional fluidized bed, as at low beds $(m / F=96)$ disappears.

The greatest influence on the bed pressure drop during fluidization is exerted by the load of the material on the supporting grid $m / F$.

Fluidization curves are also used to determine the minimum fluidization velocity of the bed, which is an important parameter for fluidized systems. The minimum fluidization velocity is mainly influenced by the size, density and shape of the particles forming the bed, as well as by the thermodynamic parameters of the fluidizing gas. The complex influence of all these factors is reflected by the Archimedes number.

For each of the experiments performed, the minimum fluidization velocity was determined from the corresponding fluidization curve. The Reynolds and Archimedes numbers for the conditions of the respective experiments were calculated and the equation for the minimum fluidization velocity was derived using the least squares method, summarizing all the experimental results. The equation is presented in the form:

$$
R e_{m f}=0,053 \cdot A r^{0,61}
$$

As a result of the conducted experiments, it was determined that the greatest influence on the bed pressure drop is the specific load of the material. Since the dependence is linear, least squares method equation for calculating the pressure drop of the bed depending on the load of the material on the supporting grid is as follows:

$$
\Delta P=9,275 \cdot \frac{m}{F}-126, \mathrm{~Pa}
$$


Table 1. Results of measurements of physical parameters and calculated values.

\begin{tabular}{|c|l|c|r|c|}
\hline No & \multicolumn{1}{|c|}{ Parameter } & Dimension & Peanuts & Cocoa beans \\
\hline $\mathbf{1}$ & Particle density & $\rho_{p}, \mathrm{~kg} / \mathrm{m}^{3}$ & 1087.000 & 960.000 \\
\hline $\mathbf{2}$ & Average equivalent particle diameter & $d_{p,}, \mathrm{~mm}$ & 10.850 & 13.700 \\
\hline $\mathbf{3}$ & Bulk density & $\rho_{b}, \mathrm{~kg} / \mathrm{m}^{3}$ & 668.000 & 578.000 \\
\hline $\mathbf{4}$ & Average dimensions of a particle & & & \\
\hline & - Depth & $B 1, \mathrm{~mm}$ & - & 12.590 \\
\hline & - Width & $B 2, \mathrm{~mm}$ & - & 8.900 \\
\hline & - Length & $H, \mathrm{~mm}$ & 15.910 & 22.240 \\
\hline & - Diameter & $D, \mathrm{~mm}^{2}$ & 8.930 & - \\
\hline $\mathbf{5}$ & Average surface of a particle & $f_{p}, \mathrm{~mm}^{2}$ & 426.790 & 636.170 \\
\hline $\mathbf{6}$ & Average volume of a particle & $V_{p}, \mathrm{~mm}^{3}$ & 770.900 & 1302.130 \\
\hline $\mathbf{7}$ & Sphericity of a particle & $\varphi_{s}$ & 0.951 & 0.900 \\
\hline $\mathbf{8}$ & Bed dispersion & $a_{f,} \mathrm{~m}^{2} / \mathrm{m}^{3}$ & 0.581 & 0.487 \\
\hline $\mathbf{9}$ & Initial porosity of the bed & $\varepsilon_{0}, \%$ & 38.540 & 38.850 \\
\hline $\mathbf{1 0}$ & Archimedes' number when temperature is & $A r .10^{-6}$ & 500.200 & 88.900 \\
& $t_{g}=20^{0} \mathrm{C}$ and pressure is $P_{b a r}=1,03.10^{5} \mathrm{~Pa}$ & & & \\
\hline
\end{tabular}

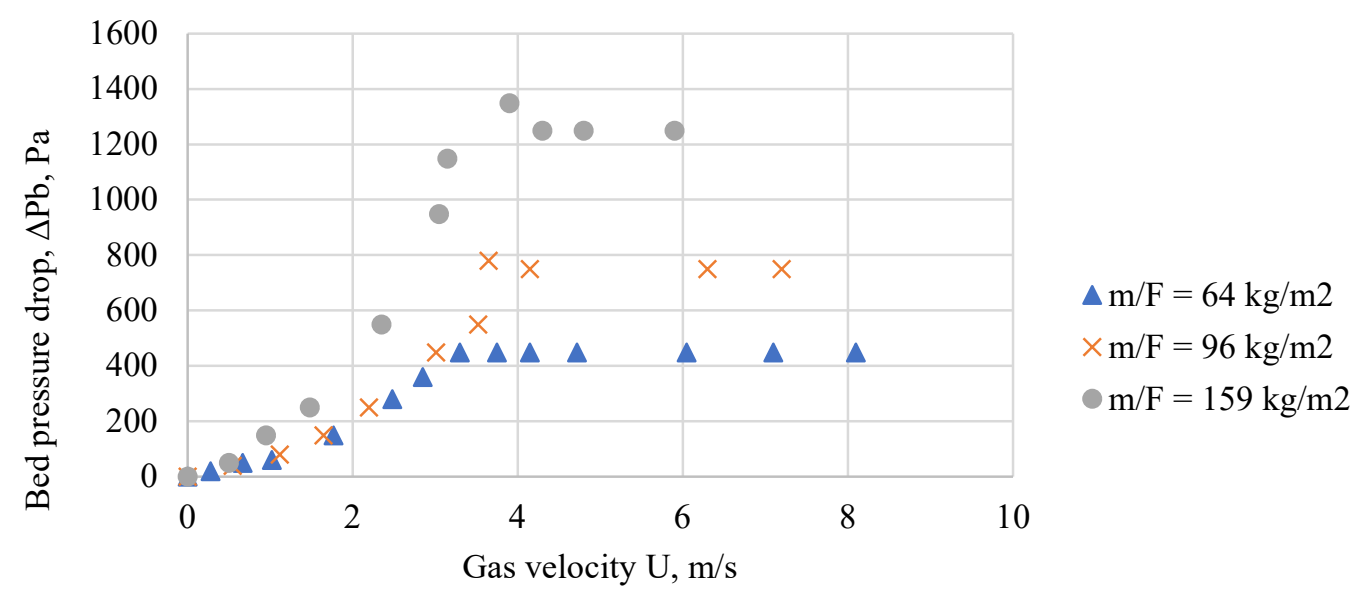

Fig. 3. Fluidization curves of peanuts at relatively opened disk cross-section $f_{\text {oed }}=7.2 \%$, disk revolutions $n=110 \mathrm{rpm}$ depending on the bed load on the grid $m / F, \mathrm{~kg} / \mathrm{m}^{2}$.

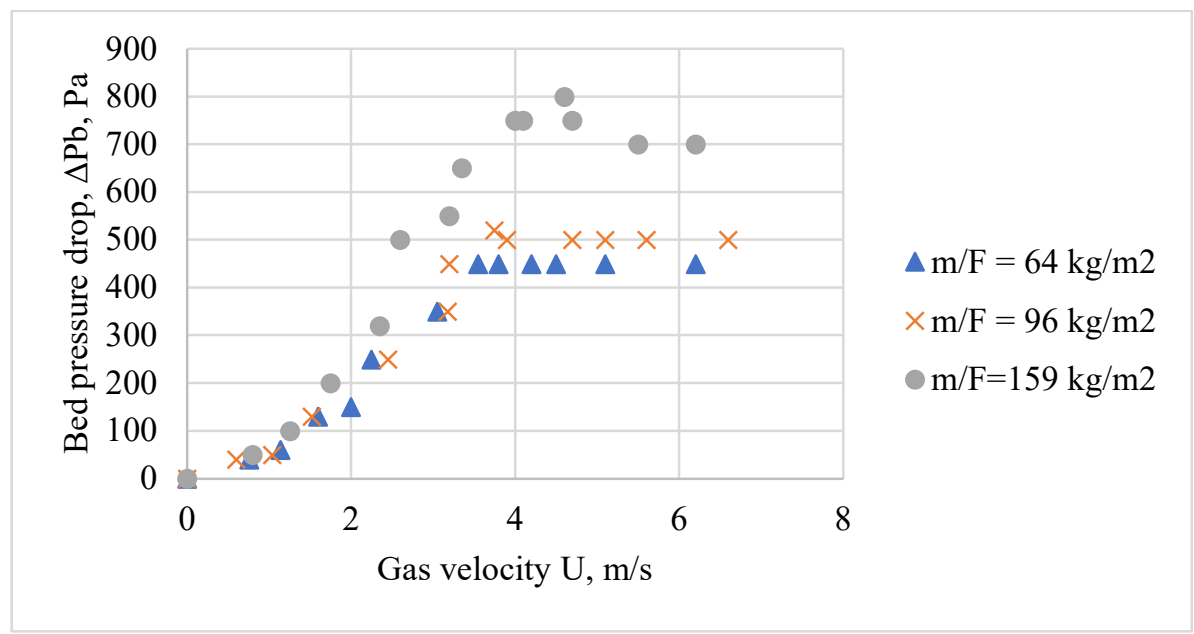

Fig. 4. Fluidization curves of cocoa beans at relatively opened disk cross section $f_{\text {oed }}=7,2 \%$, disk speed $n=23 \mathrm{rpm}$ depending on the bed load on the grid $m / F, \mathrm{~kg} / \mathrm{m}^{2}$. 


\section{Conclusions}

The hydrodynamic studies of the rotating-pulsed fluidized bed formed of peanuts and cocoa beans were carried out at various design parameters of the gas distribution device creating the fluidization.

The obtained data on the physical parameters of the products used and the calculated parameters of the formed bulk bed is the basis for choosing the optimal mode of material processing and initial data for calculating the design of raw material roasting apparatuses for the confectionary industry operating on the principle of rotating-pulse fluidization.

The derived empirical dependences for the minimum fluidization velocity (1) and calculation of the bed pressure drop (2) can be used in sizing peanut and cocoa beans with a rotating-pulsed fluidized bed.

\section{References}

1. A.Y. Oleynikova, L.M. Aksenova, G.O. Magomedov, Confectionery technology, (RAPP Publishing House, St. Petersburg, 2010)

2. S. Beckett, Industrial chocolate manufacture and use. 4th ed. (Blackwell Publishing Ltd., York, 2017)

3. C.L. Hii, AS. Menon, C.L. Chiang, S. Sharif, J. Food Proc. Eng. 40, 1-6 (2017)

4. W. Krysiak, J. Food Eng. 77, 449-453 (2006)

5. D. Żyżelewicz, W. Krysiak, J. Oracz, D. Sosnowska, G. Budryn, E. Nebesny, Food Res. Int. 89, 918-929 (2016)

6. C.L. Hii, F.M. Borém, Drying and roasting of cocoa and coffee (CRC Press, Taylor \& Francis Group, New York, 2019)

7. T.G. Djurkov, Proc. 2-nd Symp. South-East Eur. Count. Fluid. Beds Energy Prod. (Chem. Proc. Eng. Ecol., Aranjelovac, 1999)

8. T.G. Djurkov, V.R. Elenkov, Therm. Sci. An. Int. J. 4, 75-87 (2000)

9. T.G. Djurkov, Rotating-pulsed fluidized bed (Intelexpert-94 Ltd., Plovdiv, 2020)

10. J.R. Grace, X. Bi, N. Ellis, Essentials of fluidization technology (Wiley-VCH Verlag $\mathrm{GmbH} \&$ Co. Weinheim, 2020)

11. M.R. Seifi, R. Alimardani, Mod. Appl. Sci. 4, 135-143 (2010)

12. H. Masuda, K. Higashitani, H. Yoshida, Powder technology handbook, 3rd ed. (CRC Press LLC, New York, 2007)

13. S. Sahin, S.G. Sumnu, Physical properties of foods. (Springer Science+Business Media, LLC, New York, 2006)

14. J. Litster, Design and processing of particulate products (Cambridge University Press, Cambridge UK, 2016)

15. S.H. Sendov, Application of fluidized systems in industry(Technique, Sofia, 1987) 